\title{
Staff understandings of abuse and poor practice in residential settings for adults with intellectual disabilities
}

\section{Abstract}

Background: A common factor in the abuse of people with intellectual disabilities in residential settings has been the failure of care staff and frontline managers to recognise poor practice at an early stage and prevent its development into a culture of abuse. In this context, staff understandings of abuse and poor practice in residential services for people with intellectual disabilities were explored.

Method: Semi-structured interviews $(n=56)$ were undertaken with care staff and frontline managers working across England. Interviews included the use of vignettes, based on real-life experiences of people with intellectual disabilities, to prompt discussion.

Results: Staff struggled to define either 'abuse' or 'poor practice'; focussing more on individual acts or omissions than on institutional practices. When faced with vignettes staff demonstrated a lack of agreement regarding what constitutes either abuse or poor practice.

Conclusions: The implications for practice in residential care settings and for safeguarding training are discussed.

Key words: abuse; adult social care; intellectual disability; poor practice; residential care; safeguarding 


\section{Introduction}

The abuse of people with intellectual disabilities is not a new phenomenon, with scandals regularly erupting in England for over half a century (Fyson, Kitson \& Corbett, 2004). The majority (though not all) of these scandals have involved the abuse of adults with intellectual disabilities living in congregate care. The earliest of these public scandals was the abuse that occurred at Ely Hospital, Cardiff in the 1960s (Department of Health \& Social Security, 1969; Jay, 1979). Since the turn of the century there have been a number of high profile cases across a range of residential care settings including specialist NHS provision in Cornwall and South London (Healthcare Commission, 2007; Healthcare Commission \& CSCI, 2006); private hospitals Winterbourne View, near Bristol, (Flynn, 2012) and Whorlton Hall, Durham (Matthews-King, 2019); for-profit private care homes, including Veilstone in Devon where for the first time company directors were held legally responsible for the abuse of residents (Morris, 2017); and not-for profit organisations, including a National Autistic Society home in Somerset (Morris, 2018). Many of these cases show striking similarities: people with intellectual disabilities are found to have been subject to regimes of abuse; the organisation's management was complicit and/or incompetent; and abuses occurred within the context of a 'culture of abuse' involving multiple members of staff. Despite cries each time of 'never again', the problem of abuse in residential care settings remains.

In response to these scandals there have been repeated initiatives aimed at improving services for people with intellectual disabilities (Department of Health \& Social Security 1969, 1971 \& 1987; Jay, 1979; Department of Health 1993, 2001, 2007, 2012; HM Government, 2009; National Audit Office, 2017). There has also been statutory guidance, and latterly legislation, which aims to safeguard adults at risk of abuse (Department of Health \& Home Office, 2000; Care Act 2014, Department of Health, 2018). However, the effect of increased professional and, to a lesser extent, public awareness of adult safeguarding appears largely to have been an improved responsiveness to reported incidents of abuse and not an improved ability to prevent such abuses from occurring in the first place (Fyson \& Kitson, 2010 \& 2007; Fyson, 2009; CSCI, 2008; Marsland, Oakes \& White, 2007). The ongoing challenge is to prevent cultures of abuse from developing in residential care settings, rather than merely to act after abuse is uncovered. 
In the UK, and in other national contexts including USA, Australia, Republic of Korea and South Africa, the research evidence on the increased risk of abused faced by adults with disabilities is still developing (Mikton et al, 2014). However, studies investigating patterns of adult safeguarding referrals in England have identified that adults with intellectual disabilities are over-represented in referral statistics (Thacker, 2011; BeadleBrown et al, 2010; Cambridge et al, 2010; Mansell et al, 2009). UK researchers have also noted that a disproportionate number of adult safeguarding alerts emanate from residential care settings (Beadle-Brown et al, 2010; Mansell et al, 2009; ); that early indicators of abuse in residential settings are often overlooked (Marsland, Oakes \& White, 2007); and that living in residential care increases an individual's risk of suffering abuse (Cambridge et al, 2006).

Whilst research evidence relating specifically to the abuse of people with intellectual disabilities in residential care settings is limited, it is clear that poor care practices have the potential to develop into cultures of abuse (Marsland, Oakes \& White, 2007; Flynn 2012). As long ago as 1999, an in-depth study of abuse within one residential care service for people with intellectual disabilities identified the social isolation of residents, ineffectiveness of staff supervision and a lack of recognition of abuse amongst staff as contributory factors to the creation of a multi-level culture of abuse (Cambridge, 1999). A few years later, a review which sought to identify 'environments and cultures that promote [...] abuse' (White et al, 2003, p.1) emphasised the importance of staff training in preventing abuse. Despite this, more recent reviews of approaches to abuse prevention within intellectual disability services have indicated that policy and practice continue to focus on reactive responses to individual incidents of abuse rather than proactive and systemic abuse prevention (Robinson \& Chenoweth, 2011); and have noted an ongoing absence of studies evidencing the effectiveness of safeguarding governance arrangements, including law and policy, regulatory bodies and local safeguarding procedures (Braye et al, 2012).

Although it is known that poor practice can develop into cultures of abuse, poor practice is not defined within statutory safeguarding guidance. Moreover, those definitions of poor practice which exist elsewhere are not necessarily helpful: for example, Dignity in Care simply states that 'Poor practice is the opposite of good practice' $(2014$, p.7). Local Safeguarding Adults Boards typically distinguish between abuse and poor practice by stating that abuse is something which requires a response under safeguarding procedures while poor practice requires action by service provider organisations; this 
may help authorities manage the workload associated with responding to safeguarding alerts but is insufficient to guide residential care practice.

The present study sought to explore how care staff understand 'abuse', 'poor practice' and the relationship between the two, and to consider the implications of these distinctions for both organisation culture and safeguarding training.

\section{Method}

Interviews were conducted with care/support staff and frontline managers in residential care and supported living services for adults with intellectual disabilities across England. In order to ensure that the research reflected the range of service types available to people with intellectual disabilities, a number of different service provider organisations were recruited to the study. The organisations in which interviews were conducted comprised one large not-for-profit provider, one large for-profit provider and four small owner-managed care homes. Staff teams were nominated to participate by area managers of the large organisations or by the owner-manager of owner-managed homes.

In total, 56 staff were interviewed: one service manager and between three and five care staff from each of fourteen residential services. Of the staff interviewed, 40 were female and 16 were male; 48 were White British, 5 were from Black, Asian and Minority Ethnic backgrounds and 3 were White European; and job titles included 6 service managers, 3 assistant managers, 8 senior care/support workers and 39 care/support workers. Respondents' length of experience in the care sector ranged from one week to over twenty years; all except the person who had only been in post a week reported that they had received adult safeguarding training. The range of service types and number of interviews conducted in each setting is shown in table one.

[Insert table one about here]

Interviews were semi-structured and lasted between 45 and 90 minutes. Interviews started by asking participants to explain what they understood by the terms 'abuse' and 'poor practice' before moving on to present each participant with the same set of nine vignettes. Every respondent was asked to state whether they thought that each vignette 
was an example of reasonable practice, an example of poor practice or an example of abuse and to give reasons for their answer. All interviews were audio-recorded, transcribed in full and coded using NVivo software prior to analysis.

A predominantly qualitative methodology was adopted for this study because the issues at stake were matters of nuanced interpretation and deliberation by participants, making it unsuited to a positivist approach. The use of vignettes was included within the flexible context of semi-structured interviewing because of the opportunities this affords for respondents to reflect on real-life situations. Vignettes are recognised as an effective means of social research (Becker et al, 2012) which have particular value for exploring ethical and practice issues (Wallander, 2012; Taylor, 2006; Wilks, 2004). The vignettes used in this study were developed from a series of focus groups involving 25 adults with intellectual disabilities who had good verbal communication and 8 close relatives of adults with more severe intellectual disabilities and/or limited verbal communication. Every vignette derived from the real-life experiences of an adult with intellectual disability living in a residential setting; many, though not all, were regarded by focus group participants as 'not OK' (see table 3 , which provides the full text of each vignette).

Interviews transcripts were analysed using thematic content analysis (Becker et al, 2012) This involved initial coding by interview question and subsequent more detailed open coding into emergent categories. A sample of interviews was independently coded by both researchers to ensure internal reliability; synonymous categories were rationalised, and the sample was then reviewed both for consistent identification of emerging categories and the consistent application of category codes to items of data. The rationalised codes were then applied to the whole data set and subsequent analysis collapsed the emergent categories into broader themes for reporting purposes, in accordance with the method suggested by Burnard (1991). In addition, both references to specific types of abuse and data gained from the vignette categorisation exercise were analysed using descriptive statistics to quantify the numbers of participants identifying various types of abuse or selecting particular categorisations in response to vignettes.

\section{Ethics}

Ethical approval was sought and obtained (Research Register for Social Care ID no. 116382) from the Social Care Research Ethics Committee (SCIE, 2010) for England. All participants, including both interviewees and focus group members, were provided with 
information about the project prior to giving their informed consent to participation, including permission to use anonymised direct quotes in publications.

\section{Results}

The themes which emerged most strongly from the data were that respondents had differing understandings of 'abuse' and 'poor practice'; that there were contradictory understandings of the relationship between abuse and poor practice; and that, when prompted by use of vignettes to identify abuse or poor practice, there was a lack of agreement about which actions fell within either classification. These themes will each be explored in turn and their implications for understanding the development of cultures of abuse will be discussed.

No identifiable differences were found between respondents working in the for-profit sector, the not-for-profit sector or owner-managed care homes. Nor were there discernible differences between the responses of managers or support workers. Understandings of abuse and poor practice could therefore not - in this study - be linked to the presence or absence of a profit motive within the organisation's constitution or the seniority of respondents.

\section{Understanding abuse}

When asked to explain what they understood by the term 'abuse' most respondents called upon one or more of the categories from current or former statutory adult safeguarding guidelines (Department of Health, 2018; Department of Health \& Home Office, 2000). All bar one respondents had undertaken adult safeguarding training and many appeared to be actively trying to recall what they had been taught:

'Well there's financial, physical, verbal, trying to remember them now...' (I-1)

'There's loads, isn't there? Physical, verbal, financial. Loads of them. You know, anything that... neglects. You know, a lot of things.' (B-4)

'Well, it can be financial abuse of course, physical abuse, emotional abuse, abuse from neglect - not doing the job properly, [not] making sure they're eating and things like that - withholding things, so that could be abuse as well. And, one that we learnt about, institutional abuse where, you know, in a home a 
colleague's doing it and you might all follow suit. But, yes, those are the main aren't they: financial, physical, emotional.' (F-2)

Although the last of the above quotes mentions institutional abuse, this was one of only three interviewees to do so. From the perspective of interviewees, abuse was almost exclusively regarded as something which specific staff were responsible for inflicting upon services users, through their actions or inactions. Physical abuse was the most frequently-mentioned form of abuse, being referred to by $77 \%$ of interviewees; it was sometimes stated to be the 'worst' kind of abuse:

'I mean, I personally think physical abuse is obviously the worst, but any type of abuse is serious and should be reported.' (A-1)

The second most frequently-mentioned type of abuse was financial abuse (63\%), followed by psychological or emotional abuse (48\%) and sexual abuse (41\%). Full details of all types of abuse mentioned are shown in table two, together with the number of interviewees who made use of each category.

[Insert table two about here]

Having started from these pre-existing categories interviewees elaborated and, from their further deliberations, three distinct elements emerged. Firstly, understandings of abuse as a denial of choice:

'Abuse is [...] not giving them a choice on things.' (L-4)

Secondly, abuse as a failure to uphold basic tenets of respect, dignity and human rights:

'It's an abusive thing if you're not respecting people's dignity, rights, choices.' (A1)

'You take their [the service users'] values into consideration and obviously their opinions. And obviously, if you don't respect that, obviously you're abusing them, aren't you? You've got to treat everybody as an individual and respect their views.' (E-3)

'People have rights and certain needs and if you are impeding on those rights then you are kind of abusing them. So you have to understand that there are certain basic rights that people do have and if you go beyond those rights you are already abusing them.' (A-2)

And, thirdly, consideration of whether abuse was always intentional, or could also occur 
inadvertently through ignorance or accident:

'I think, with abuse, a lot of the time people know what they're doing to somebody is wrong. Whereas poor practice or bad practice - however you want to say it - a lot of the time they may not be aware what they're doing is wrong'. $(\mathrm{L}-3)$

Less than a quarter of interviewees (12/56) tried to conceptualise, rather than categorise, abuse. Those that did tended share a focus on what might be termed 'relational dynamics' (i.e. a considerations of self and others) but beyond this fell into two distinct groups. Firstly, there were eight who took a broadly Kantian 'do as you would be done by' approach (Scruton, 2001), as in the following examples:

'It's anything you or I wouldn't want happening to us is abuse, basically.' (A-5)

'Something that harms them; something that you wouldn't have done to yourself.' (L-2)

And there were another four whose conceptualisation could be characterised as Foucauldian (Gutting, 2005), with abuse constructed as deriving from unequal power relations:

'It's when somebody is in a place of power and they're abusing that power or trust.' (J-3)

'We as staff are very, very powerful [...] and sometimes you get staff who are very sort of weak willed in open society and because they all of a sudden become quite powerful that's maybe their... when their abuse starts. And I've known people who are... wouldn't say boo to a goose in ordinary social company that have turned out to be actually really bad abusers because I just think that they enjoyed that little section of power that they were given.' (F-1)

Overall, most interviewees went beyond listing types of abuse to consider contextualising factors such as (lack of) choice and respect or the relational dynamics that contribute to abuse. This engagement with complexity was even more evident when interviewees talked about poor practice.

\section{Understanding poor practice}

When first asked to explain what they understood by the term 'poor practice', respondents found this a challenge, perhaps because there are no accepted definitions of 
poor practice to fall back on. Nevertheless, several phrases were heard repeatedly. These included: 'not following policies'; 'not doing the job properly'; 'cutting corners'; 'not giving choices' or 'staff just thinking of themselves' and also as 'simple things' or 'just small things, but they can make a big difference in their [service users'] lives' (I-1).

It was notable that, in contrast to their understandings of abuse, interviewees recognised poor practice as something which could derive either from the actions or inactions of staff or from the consequences of organisational and managerial failures, as in the following examples:

'Poor practice, I think, would be if the organisation's not giving the right amount of training so staff don't know what their responsibilities are.' (C-1) 'Poor practice is if we have no policies, or poor policies that aren't followed by staff because obviously staff need to be aware of boundaries and guidelines.' (F1)

Although the phrase 'organisational culture' was not used by any interviewee, this concept was evident within the data - as in the following two examples where interviewees describe how cultures of poor practice could develop or continue:

'I think poor practice would be sort of [...] if you've got like a sort of senior team and they're doing things that are questionable. And then new staff come in and they kind of learn the sort of bad things they're doing. And they sort of assume it to be okay.' (A-5)

'I think there can be poor practice without people deliberately choosing to do poor practice. If you're not trained and you don't have the understanding of people, I think it can sort of continue until someone picks up on it. And it's not done in a deliberate negative way, but it is easy, I suppose, for that to happen. You sort of fall into habits kind of thing, don't you?' (N-3)

Alongside the recognition that poor practice could be linked to both individual actions or organisational cultures, was evidence of the important role played by managers in either combatting poor practice or permitting it to flourish. Managers were seen as responsible for setting the tone of an organisation's culture, with poor practice being something that would 'probably start from the top; you know, if your manager wasn't 100\% caring or dedicated' (F-2), and as culpable when poor practice developed because of their failure to recognise its encroachment: '[poor practice] can just be how you do things in that 
unit; it could be the whole staff team working to that level and the manager doesn't even realise' $(\mathrm{N}-2)$. At the same time, managers were also regarded as central to the prevention of poor practice, with one interviewee commenting that 'you're only as good as your manager is' ( $\mathrm{J}-1)$.

\section{The relationship between abuse and poor practice}

As the preceding quotes have demonstrated, there were several points at which respondents' understandings of abuse overlapped with their understandings of poor practice. Choice was mentioned repeatedly in relation to both abuse and poor practice, as were questions of staff culpability - arising variously from ignorance, lack of training and/or poor management. However, when interviewees were asked directly about the relationship between abuse and poor practice there was disagreement about whether these were distinct or overlapping categories.

Just two respondents thought that abuse and poor practice were separate things:

Interviewer: 'Do you think that there's any overlap between abuse and poor practice?' Interviewee: 'No. Because abuse is severely wrong and poor practice, I think, just needs a bit more training and pointing back in the right direction to stop it happening. It's not something that's going to cause them harm, which abuse will; it will just cause frustration.' (L-2)

The vast majority believed there to be an area of overlap between abuse and poor practice, emphasising how 'it's a thin line for abuse and poor practice' and understanding them as part of the same phenomenon:

'I think, when you first say it, I think you would think that they were very different. But actually, when you think about it, I think they are quite similar.' (N2)

'All abuse will come under bad practice, [but] I don't think all bad practice will come under abuse.' (J-3)

One interviewee also spoke about how poor practice needed to be taken seriously as it could be 'an indicator' of abuse:

'Poor practice can be an indicator that something else might be happening. [...] That might be abuse or it could be that it's just poor practice and that member of 
staff needs some guidance and training. [...] I'd look for patterns and look into it a bit more.' (L-4)

And another gave specific examples of how and why the same action could be considered to be either abuse or poor practice:

'Poor practice is, I think, people who've had a lack of training and don't understand that it probably is abuse. You know, if you - instead of knocking on somebody's door - are just walking into somebody's bedroom [...] actually it is abuse. But for somebody who just started working there, then it's poor practice'. $(\mathrm{J}-2)$

In the above quote, it is evident that in considering whether something is abuse or 'just' poor practice the interviewee is only taking account of the staff perspective. The thought process is clear: staff can be forgiven for abusive practices if they are new or untrained. There is no attempt to view the situation from the perspective of the service user, who will have had their privacy violated regardless of whether the member of staff acted naively or in full knowledge that this was wrong.

Interviewees' attempts to explain abuse and poor practice revealed some broadly shared understandings, notably the idea that abuse and poor practice were essentially subjective in nature and were (for most) overlapping categories. This suggests the existence of at least some degree of shared understandings of abuse and poor practice. By contrast, the response to real-life vignettes revealed the extent to which applied interpretations of both abuse and poor practice were highly individualised.

\section{Recognising abuse and poor practice}

Having first considered respondents' understandings of abuse and poor practice, the interviewer asked participants to categorise nine different vignettes as either 'reasonable practice' or 'poor practice' or 'abuse'. In introducing the vignettes, the interviewer emphasised that there was no definitive right or wrong answer and requested that the interviewee explain the reasoning behind their choice of categories. The full text of each vignette, together with interviewees' categorisations, is shown in table three. The table also shows the consensus view of people with intellectual disabilities on whether the vignette did or did not portray abuse.

[Insert table 3 about here] 
The most striking finding to emerge from the vignettes was the diversity of respondents' views, amounting to a complete lack of agreement about whether the care practices depicted were reasonable, poor practice or abuse. For each vignette, at least one interviewee interpreted the situation as reasonable practice, whilst others saw it as poor practice and at least one other classified it as abuse.

So, for example, in response to vignette six (in which residents' laundry is muddled up), although the majority (82.1\%) of interviewees saw this as an example of poor practice, a few $(7.1 \%)$ saw it as reasonable on the grounds that 'this happens' and was both inevitable and unintentional, whilst a few others (8.9\%) defined it as abuse on the basis that these were people's personal possessions, had the potential to cause infection, and because the situation was created by staff not making the effort to do things properly. A range of practical solutions to this issue was offered but, regardless of how individuals classified the vignette, it was recognised as something which in the context of residential services was culturally normative. By contrast, people with intellectual disability were clear that this was 'not OK'.

Similarly, in response to vignette three (in which a resident is denied a birthday celebration in the local pub due to a shortage of staff) the reactions ranged from regarding this as reasonable and understandable ('that's life'); through viewing it as poor practice, but needing to be 'realistic' about what can be done with reduced staff; to seeing the situation as abusive because birthdays are important, are always known about in advance, and should therefore be planned for. One interviewee commented that if a birthday celebration for one of their service users was cancelled 'we'd have a riot' and another said 'I would have come in specially'. This scenario was included as an example of institutional abuse - i.e. the negative outcomes were associated with organisational structures, practices and resources rather than with the action or inaction of a particular member of staff. Of the vignettes deemed 'not OK' by people with intellectual disabilities, this attracted the highest proportion (32.1\%) of 'reasonable practice' responses from staff. This suggests that staff may be less likely to recognise institutional - rather than individual - forms of abuse or poor practice.

The vignette which attracted the most consistent response (number seven, in which a service user is saving money for a holiday) was the one which was most readily interpreted as reasonable practice with $91.1 \%$ agreement. People with intellectual 
disabilities also thought this was 'OK'. However, the deliberations of the staff respondents who thought differently, or were unable to come to a conclusion, were noteworthy: they emphasised that such actions were reasonable only so long as they reflected the wishes of the service user in question; and, as they pointed out, it could not be assumed that a decision to go on holiday had been taken with the service users' full involvement. A similar response, i.e. broad agreement but with a small number of outliers, was evident in response to the second vignette (in which all residents are expected to give money towards a staff members' leaving present). In this case the vast majority $(82.1 \%)$ thought that the scenario was an example of abuse, but small proportions found it to be poor $(12.5 \%)$ or reasonable $(1.8 \%)$ practice.

By contrast, the vignettes which generated the most diverse responses (number four, in which a member of staff brings in a horror DVD and number nine in which a resident's unhealthy choice of diet is unchallenged) were both situations in which complex invocations of 'choice' were played out. In the first instance, the complexity centred on the conflicting choices of different residents sharing the same home. In the second instance, the complexity derived from the relationship between choice and capacity, and the tension between on the one hand freedom to choose in the here-and-now and on the other the potential lack of understanding of longer-term consequences.

\section{Limitations of the study}

The characteristics of interviewees, in terms of gender and ethnicity, broadly reflected those of the wider social care workforce (Skills for Care, 2018). However, the study may not be representative of all residential homes and supported living services for people with intellectual disabilities in England. Two large for-profit organisations and several owner-managed care homes declined to participate in the study. This was despite the fact that the request for involvement included an offer to pay the organisation for their staff's time. It is likely that organisations were deterred from participating because of the topic, i.e. they were not willing to come under scrutiny in relation to safeguarding. The overall findings should be considered in light of this; the typical level of awareness and understanding of abuse and poor practice amongst care and support workers may be different than the present findings suggest. Furthermore, staff identification of abuse in hypothetical situations may not correspond to recognising and reporting abuse in practice. The study did not address the important issue of abuse perpetrated by service users on other service users. Nevertheless, these findings do provide insights into staff 
understandings of abuse and poor practice which have implications for our understanding of cultures of abuse and for the content of safeguarding training.

\section{Discussion}

This study has provided new insights into staff understandings of abuse and poor practice. Firstly, it showed how staff understandings of abuse tend to centre on recalling categories of abuse as they appear in policy guidelines. Secondly, it identified that staff think about abuse largely in terms of individual acts of commission or omission and place less emphasis on institutional abuse. Thirdly, it demonstrated that (most) staff recognise that there is some degree of overlap between abuse and poor practice. Fourthly, it revealed that, when presented with real-life scenarios, staff held unpredictable views as to whether or not specific situations amounted to abuse; with the majority views of staff not necessarily coinciding with those of people with intellectual disabilities. These findings have implications for the content of safeguarding training and for understanding how cultures of abuse may develop.

Staff predominantly defined abuse by starting with individual acts and then 'adding on' other considerations such as (lack of) choice and respect; very few mentioned institutional abuse despite the fact that interviewees often appeared to be recalling a list of 'types of abuse' learnt during training. This suggests that safeguarding training may not be effective at enabling residential care staff to think of abuse - particularly institutional abuse - as something that could happen where they work. Safeguarding training (and care home managers) needs to directly address the "It could never happen here" mentality (c.f. ARC/NAPSAC, 1993).

It was further notable that staff understanding of abuse seldom started from a relational perspective - i.e. as something grounded in unequal power relations or something to be measured in comparison to how you yourself would like to be treated. It is not known whether relational concepts were discussed during safeguarding training, but no interviewee ascribed their relational thinking to training they had received. This suggests that safeguarding training may benefit from increased consideration of the relational dynamics of abuse. 
Participants' considerations of poor practice were more expansive. There was an understanding that poor practice is associated with organisational culture in general, and the quality of management in particular. Furthermore, most staff recognised that there was an overlap or continuum between poor practice and abuse. Nevertheless, the diverse response to vignettes highlighted how, although interviewees shared some conceptual approaches poor practice, there was little consensus about how such conceptualisations should be applied in practice. A divergence between the response of staff and the response of people with intellectual disabilities to some vignettes was also noted. The views of people with intellectual disabilities do not necessarily constitute some form of higher 'truth' about what is and is not abusive. However, this finding does point to a need for staff to better understand how their actions (or inactions), and the culture which is thereby created in each residential care setting, impact on the people with intellectual disabilities who live there.

Understandings of abuse and poor practice contribute to how residential care staff practise. Thinking of abuse primarily as an individual act will limit considerations of how institutional practices impact upon service users. This does not lead automatically or inexorably to a culture of abuse, but in some circumstances could lay the foundations for a culture of abuse to develop. Part of the reason for this is that the social boundaries that ordinarily govern interpersonal behaviour are routinely and necessarily breached in the course of providing care (for example, staff may see and touch residents who are naked in order to provide intimate personal care). This has the potential to make it easier for staff to breach other social norms of behaviour. In such a way cultures of abuse may take root. This is not to suggest that all care staff are liable to become abusers, nor is it to excuse those who participate in abuse. It is merely to identify one possible mechanism whereby abusive institutional practices pass unrecognised and so become culturally normative in that context. Other mechanisms and influences also play a part, not least wider social attitudes which dehumanise people with intellectual disability (Rogers, 2016). If safeguarding training does not actively challenge dehumanising attitudes towards people with intellectual disabilities, then such attitudes also provide a basis from which cultures of abuse can develop.

\section{Conclusion}

People with intellectual disabilities who live in residential settings spend more time with care and support staff than with their family or with other professionals. When abuse 
takes place in such settings, staff are often identified as perpetrators. However, staff are also the first line of defence against abuse and, if residential care settings are to be made safer, staff are key. Where safeguarding training - deliberately or otherwise encourages staff to think about abuse predominantly in terms of individual acts, then it is unlikely to equip them to question organisational practices and institutional norms. This has the potential to allow patterns of poor and abusive practice to emerge and persist without being challenged.

Events at Winterbourne View, Whorlton Hall and elsewhere have demonstrated that a collective failure to identify and take action against poor practice can enable cultures of horrific abuse to develop and flourish. Whilst safeguarding action in response to such abuse is important, the ultimate goal must be to prevent abuse from occurring in the first place. For this to happen, safeguarding training needs to support staff to understand abuse and poor practice not only as individual acts or omissions but also as a set of relational dynamics which can create and sustain either positive or abusive institutional cultures.

\section{References}

ARC/NAPSAC (1993) It Could Never Happen Here!: Prevention and Treatment of Sexual Abuse of Adults with Learning Disabilities in Residential Settings, Chesterfield/Nottingham: ARC/NAPSAC

Becker, S., Bryman, A. \& Ferguson, H. [eds.] (2012) Understanding Research for Social Policy and Social Work: Themes, Methods and Approaches [2nd edition] Bristol: Policy Press

Beadle-Brown, J., Mansell, J., Cambridge, P., Milne, A. \& Whetton, B. (2010) Adult Protection of People with Intellectual Disabilities: Incidence, Nature \& Responses. Journal of Applied Research in Intellectual Disability 23 (6) 573-584

Bennet, D., Flood, S., Howarth, J., Melsome, M. \& Northway, R. (2013) Looking into Abuse: Research by People with Learning Disabilities, UDID: University of South Wales http://udid.research.southwales.ac.uk/media/files/documents/2013-0305/Final report.pdf

Braye, S., Orr, D. \& Preston-Shoot, M. (2012) The Governance of Adult Safeguarding: Findings from Research, Journal of Adult Protection 14 (2) 55-72 
Burnard, P. (1991) A method of analysing interview transcripts in qualitative research, Nurse Education Today, 6 (11) 461-466

Cambridge, P. (1999) The first hit: a case study of the physical abuse of people with learning disabilities and challenging behaviours in a residential service, Disability \& Society, 14 (3) 285308

Cambridge, P., Beadle-Brown, J., Milne, A., Mansell, J. \& Whelton, B. (2006) Exploring the incidence, risk factors, nature and monitoring of adult protection alerts Canterbury: Tizard Centre

Cambridge, P., Beadle-Brown, J., Milne, A., Mansell, J. \& Whelton, B. (2010) Adult Protection: The processes and Outcomes of adult protection referrals in two English local authorities, Journal of Social Work, 11 (3) 247-267

Care Act 2014 http://www.legislation.gov.uk/ukpga/2014/23/section/1/enacted

Clement, T. \& Bigby, C. (2009) Group Homes for People with Intellectual Disabilities: Encouraging Inclusion \& Participation London: Jessica Kingsley

CSCI (2008) Safeguarding Adults: A study of the effectiveness of arrangements to safeguard adults from abuse London: CSCI

Department of Health (1993) Services for people with learning disabilities and challenging behaviour or mental health needs: Report of a Project Group (Chairman: Prof J L Mansell). London: Her Majesty's Stationery Office

Department of Health (2001) Valuing people: a new strategy for learning disability for the 21st century [Cm 5086] London: The Stationery Office

Department of Health (2007) Services for people with learning disabilities and challenging behaviour or mental health needs: Report of a Project Group (Chairman: Prof J L Mansell) (Revised Edition) London: Department of Health

Department of Health (2012) Transforming care: A national response to Winterbourne View Hospital. London: Department of Health

Department of Health \& Social Care (2018) Care Act Statutory Guidance, updated 12 February 2018 https://www.gov.uk/government/publications/care-act-statutoryguidance/care-andsupport-statutory-guidance

Department of Health and Social Security (1969) Report of the Committee of Inquiry into Allegations of IIl - Treatment of Patients and other irregularities at the Ely Hospital, Cardiff [Cm3975] London: HMSO

Department of Health and Social Security (1971) Better Services for the Mentally Handicapped [Cm 4683] London: HMSO

Department of Health and Social Security (1987) Mental Handicap - Progress, Problems and Priorities: Review of Mental Handicap Services in England since the 1971 
White Paper "Better Services for the Mentally Handicapped" London: The Stationery Office

Department of Health and Home Office (2000) No Secrets: guidance on developing and implementing multi-agency policies and procedures to protect vulnerable adults from abuse, London: The Stationery Office

Dignity in Care (2014) Challenging Poor Practice - Training module

https://www.dignityincare.org.uk/Resources/Type/Challenging-Poor-PracticeTraining-module/

Flynn, M (2012) Winterbourne View Hospital: A Serious Case Review, South Gloucestershire Safeguarding Adults Board

Fyson, R (2009) Independence and learning disabilities: why we must also recognise vulnerability. Journal of Adult Protection 11 (3) 18-25

Fyson, R \& Kitson, D (2007) Independence or Protection - does it have to be a choice?: Reflections on the abuse people with learning disabilities in Cornwall. Critical Social Policy 27 (3) 426-436

Fyson, R \& Kitson, D (2010) Human rights and social wrongs: issues in safeguarding adults with learning disabilities Practice: Social Work in Action 22 (5) 309-320

Fyson, R, Kitson, D \& Corbett, A (2004) Learning Disability, Abuse \& Inquiry In: N. Stanley \& J. Manthorpe (eds.) The Age of The Inquiry: learning and blaming in health and social care. London: Routledge

Gutting, G (2005) Foucault: A Very Short Introduction, Oxford: Oxford University Press Healthcare Commission (2007), Investigation into the service for people with learning disabilities at Sutton and Merton Primary Care Trust, London: Commission for Healthcare Audit \& Inspection

Healthcare Commission \& CSCI (2006) Joint Investigation into the Provision of Services for People with Learning Disabilities at Cornwall Partnership NHS Trust, London: Commission for Healthcare Audit \& Inspection

HM Government (2009) Valuing People now: a new three-year strategy for people with learning disabilities. London: Department of Health.

Jay, P. (1979) Report of the Committee of Enquiry into Mental Handicap Nursing and Care (Cm 7468) London: HMSO

Johnson, F. (2012a) Problems with the Term and Concept of 'Abuse': Critical Reflections on the Scottish Adult Support and Protection Study, British Journal of Social Work 42 (5) $833-850$ 
Johnson, F. (2012b) What is an 'adult protection' issue? Victims, perpetrators and the professional construction of adult protection issues, Critical Social Policy 32 (2) 203-222

Mansell, J., Beadle-Brown, J., Cambridge, P., Milne, A. \& Whelton, B. (2009) Adult Protection: Incidence of Referrals, Nature and Risk Factors in Two English Local Authorities, Journal of Social Work, 9 (1) 23-38

Manthorpe, J., Stevens, M., Rapaport, J., Challis,D., Jacobs, S., Netten, A., Jones, K., Knapp, M., Wilberforce, M. \& Glendinning, C. (2011) Individual budgets and adult safeguarding: Parallel or converging tracks? Further findings from the evaluation of the Individual Budget pilots, Journal of Social Work, 11 (4) 422-438

Marsland, D., Oakes, P. \& White, C. (2007) Abuse in care? The identification of early indicators of the abuse of people with learning disabilities in residential settings, Journal of Adult Protection, 9 (4) 6-20

Matthews-King (2019) Whorlton Hall investigation: 10 arrested over care home 'abuse' of patients with learning disabilities. The Independent, 24 May 2019 https://www.independent.co.uk/news/health/whorlton-hall-investigation-arrests-abuselearning-disability-latest-a8928811.html

Mikton, C., Maguire, H. \& Shakespeare, T. (2014) A Systematic Review of the Effectiveness of Interventions to Prevent and Respond to Violence Against Persons with Disabilities, Journal of Interpersonal Violence, 29 (17) 3207-3226

Morris, S (2017) Care home directors convicted over 'horrific' learning disability regime, The Guardian, 7 June 2017

https://www.thequardian.com/society/2017/jun/07/care-homedirectorsconvicted-over-devon-learning-disability-regime

Morris, S (2018) Somerset care home staff bullied autistic residents, review finds. The Guardian 8 February 2018 https://www.theguardian.com/society/2018/feb/08/somerset-care-home-staffbullied-autistic-residents-review-finds

National Audit Office (2017) Local support for people with a learning disability: Report by the Comptroller and Auditor General https://www.Local-support-for-people-witha-learning-disability.pdf

Robinson, S. \& Chenoweth, L. (2011) Preventing abuse in accommodation services: From procedural response to protective cultures, Journal of Intellectual Disabilities, 15 (1) 63-74

Rogers, C. (2016) Intellectual Disability and Being Human. London: Routledge 
SCIE (2010) Social Care Research Ethics Committee: SCIE web resource

http://www.scie.org.uk/topic/developingskillsservices/socialcareresearchethicsco $\underline{\text { mmittee }}$

Scruton, R. (2001) Kant: A Very Short Introduction, Oxford: Oxford University Press

Taylor, B. (2006) Factorial Surveys: Using Vignettes to Study Professional Judgement, British Journal of Social Work, 36 (7) 1187-1207

Taylor, C. \& White S. (2001) Knowledge, Truth and Reflexivity: The Problem of Judgement in Social Work, Journal of Social Work, 1 (1) 37-59

Thacker, H. (2011) Safeguarding adults' referrals in the Eastern region: an investigation into varying referrals rates, Journal of Adult Protection, 11 (3) 137-149

Wallander, L. (2012) Measuring social workers' judgements: Why and how to use the factorial survey approach in the study of professional judgements, Journal of Social Work, 12 (4) 364-384

White, C., Holland, E., Marsland, D. \& Oakes, P. (2003) The Identifications of Environments and Cultures that Promote the Abuse of People with Intellectual Disabilities: A Review of the Literature. Journal of Applied Research in Intellectual Disability 16 (1) 1-9

Wilks, T (2004) The Use of Vignettes in Qualitative Research into Social Work Values, Qualitative Social Work, 3 (1) 78-87 
Table one: interviews

\begin{tabular}{|l|c|c|c|}
\hline & $\begin{array}{l}\text { No. of } \\
\text { participating } \\
\text { homes/ supported } \\
\text { living services }\end{array}$ & $\begin{array}{l}\text { No. of service } \\
\text { managers } \\
\text { interviewed }\end{array}$ & $\begin{array}{l}\text { No. of } \\
\text { care/support } \\
\text { workers } \\
\text { interviewed }\end{array}$ \\
\hline $\begin{array}{l}\text { For-profit } \\
\text { provider }\end{array}$ & 5 & 1 & 19 \\
\hline $\begin{array}{l}\text { Not-for-profit } \\
\text { provider }\end{array}$ & 5 & 1 & 17 \\
\hline Owner-managed & 4 & 4 & 14 \\
\hline Total & 14 & 6 & 50 \\
\hline
\end{tabular}

Table two: types of abuse identified

\begin{tabular}{|l|c|c|}
\hline & $\begin{array}{l}\text { No. who } \\
\text { mentioned this } \\
\text { type of abuse }\end{array}$ & $\begin{array}{l}\text { \% who mentioned } \\
\text { this type of abuse }\end{array}$ \\
\hline Physical & 43 & $77 \%$ \\
\hline Financial & 35 & $63 \%$ \\
\hline Psychological/emotional/mental & 27 & $48 \%$ \\
\hline Sexual & 23 & $41 \%$ \\
\hline Bullying/verbal & 19 & $34 \%$ \\
\hline Neglect & 13 & $23 \%$ \\
\hline Discrimination & 4 & $7 \%$ \\
\hline Institutional & 3 & $5 \%$ \\
\hline Theft/stealing & 2 & $4 \%$ \\
\hline Medical/misuse of medication & 2 & $4 \%$ \\
\hline
\end{tabular}


Table three: responses to vignettes

\begin{tabular}{|c|c|c|c|c|c|}
\hline Vignette & $\begin{array}{l}\text { Reasonable } \\
\text { practice }\end{array}$ & $\begin{array}{l}\text { Poor } \\
\text { practice }\end{array}$ & Abuse & $\begin{array}{l}\text { Could } \\
\text { not } \\
\text { decide }\end{array}$ & $\begin{array}{l}\text { View of } \\
\text { people } \\
\text { with } \\
\text { intellectual } \\
\text { disabilities }\end{array}$ \\
\hline $\begin{array}{l}\text { 1. A resident repeatedly expresses } \\
\text { his unhappiness with where he } \\
\text { is living - support staff respond } \\
\text { to this by telling him to cheer up } \\
\text { and that everything will be okay. }\end{array}$ & $\begin{array}{c}3 \\
(5.4 \%)\end{array}$ & $\begin{array}{c}39 \\
(69.9 \%)\end{array}$ & $\begin{array}{c}11 \\
(19.6 \%)\end{array}$ & $\begin{array}{c}3 \\
(5.4 \%)\end{array}$ & Not OK \\
\hline $\begin{array}{l}\text { 2. A member of staff is leaving. All } \\
\text { residents are expected to } \\
\text { contribute } f 10 \text { towards a leaving } \\
\text { present. }\end{array}$ & $\begin{array}{c}1 \\
(1.8 \%)\end{array}$ & $\begin{array}{c}7 \\
(12.5 \%)\end{array}$ & $\begin{array}{c}46 \\
(82.1 \%)\end{array}$ & $\begin{array}{c}2 \\
(1.8 \%)\end{array}$ & Not OK \\
\hline $\begin{array}{l}\text { 3. It's a resident's birthday and she } \\
\text { has expressed a wish to go out } \\
\text { to celebrate in the local pub. On } \\
\text { the actual day she is told that } \\
\text { there are not enough staff on } \\
\text { duty, so she stays in and has } \\
\text { cake with other residents. }\end{array}$ & $\begin{array}{c}18 \\
(32.1 \%)\end{array}$ & $\begin{array}{c}27 \\
(48.2 \%)\end{array}$ & $\begin{array}{c}7 \\
(12.5 \%)\end{array}$ & $\begin{array}{c}4 \\
(7.1 \%)\end{array}$ & Not OK \\
\hline $\begin{array}{l}\text { 4. On a Saturday evening shift a } \\
\text { member of staff brings in horror } \\
\text { film on DVD. A resident who is } \\
\text { scared of horror films is told to } \\
\text { watch TV in her own room. }\end{array}$ & $\begin{array}{c}3 \\
(5.4 \%)\end{array}$ & $\begin{array}{c}23 \\
(41.1 \%)\end{array}$ & $\begin{array}{c}24 \\
(42.9 \%)\end{array}$ & $\begin{array}{c}6 \\
(10.7 \%)\end{array}$ & Not OK \\
\hline $\begin{array}{l}\text { 5. A resident is cajoled into doing } \\
\text { her share of the cleaning before } \\
\text { she goes out shopping for the } \\
\text { afternoon. }\end{array}$ & $\begin{array}{c}42 \\
(75 \%)\end{array}$ & $\begin{array}{c}8 \\
(14.3 \%)\end{array}$ & $\begin{array}{c}5 \\
(8.9 \%)\end{array}$ & $\begin{array}{c}1 \\
(1.8 \%)\end{array}$ & OK \\
\hline $\begin{array}{l}\text { 6. The laundry often gets muddled } \\
\text { up so that residents end up } \\
\text { wearing each other's clothes. }\end{array}$ & $\begin{array}{c}4 \\
(7.1 \%)\end{array}$ & $\begin{array}{c}46 \\
(82.1 \%)\end{array}$ & $\begin{array}{c}5 \\
(8.9 \%)\end{array}$ & $\begin{array}{c}1 \\
(1.8 \%)\end{array}$ & Not OK \\
\hline $\begin{array}{l}\text { 7. A resident only has a limited } \\
\text { amount of money each week to } \\
\text { spend as they choose, whilst } \\
\text { they are saving for a holiday. }\end{array}$ & $\begin{array}{c}51 \\
(91.1 \%)\end{array}$ & $\begin{array}{c}1 \\
(1.8 \%)\end{array}$ & $\begin{array}{c}1 \\
(1.8 \%)\end{array}$ & $\begin{array}{c}3 \\
(5.4 \%)\end{array}$ & OK \\
\hline $\begin{array}{l}\text { 8. A resident has a suspected ear } \\
\text { infection and needs to see the } \\
\text { doctor but when their behaviour } \\
\text { becomes challenging the } \\
\text { appointment is cancelled. }\end{array}$ & $\begin{array}{c}6 \\
(10.7 \%)\end{array}$ & $\begin{array}{c}9 \\
(16.1 \%)\end{array}$ & $\begin{array}{c}37 \\
166.1 \%\end{array}$ & $\begin{array}{c}4 \\
(7.1 \%)\end{array}$ & Not OK \\
\hline $\begin{array}{l}\text { 9. An obese resident lives on a diet } \\
\text { of McDonalds, pizza and fizzy } \\
\text { pop. Staff do not try to change } \\
\text { his diet because it is his choice. }\end{array}$ & $\begin{array}{c}3 \\
(5.4 \%)\end{array}$ & $\begin{array}{c}22 \\
(39.3 \%)\end{array}$ & $\begin{array}{c}27 \\
(48.2 \%)\end{array}$ & $\begin{array}{c}4 \\
(7.1 \%)\end{array}$ & Not OK \\
\hline
\end{tabular}

